\title{
REDRAWING HISTORICAL ILLUSTRATIONS IN RESEARCH OF GENUINE URBAN FEATURES
}

\author{
Zoltan MAROȘI \\ Babeş-Bolyai University, Cluj-Napoca, Faculty of Geography and Centre for Research on Settlements and Urbanism, \\ ROMANIA \\ zoltan_marosi@yahoo.de
}

DOI: http://dx.medra.org/10.23740/TID120163

\section{ABSTRACT}

As a part of an extensive qualitative research, using historical illustrations of all kinds was strongly encouraged by the recent improvements in graphics software; once rarely seen documents and illustrations are now available in an infinite number of virtual copies, ready for restoration, interpretation, and assessments. The interest for historical illustrations is more pronounced in marketing, when a local brand or a product is promoted by the local history, often using the past as a reminder of the bonds between inhabitants and places. However, the most popular way to use historical illustrations can be found in art, while the main purpose of this paper is to encourage the use of these pictures, maps and documents in urban research and planning. In this paper, we recommend a path to reduce subjectivity while using historical illustrations and the practical results that can be achieved.

Keywords: historical illustrations, urban planning, representation, urban identity, Cluj-Napoca

\section{INTRODUCTION}

Drawings have always been a good substitute, used for effective teaching and learning, often becoming a way to overcome the barrier between imagination and creation. However, in the digital and virtual age, the convenience to take photographs caused a decrease of interest for drawing, even among architects, planners and designers, who mostly rely on graphics software. In this specific case, architect Scheer (2014) describes an architecture seminar in which students were asked to find differences between a drawn portrait of a friend and a photograph of him or her. Surprisingly, their answer was unanimous: that photograph was more realistic than the drawing (Scheer, 2014, pp. 19-49). The unexpected simple answer given by those students reveals that they judge an image solely on its realism, they thought in term of simulation supported by their electronically mediated relationships, "therefore simulation has displaced representation in architecture and society at large" (Scheer, 2014, p. 20).

However, drawing in the age of digital simulations should not be regarded with nostalgia, simulation as an imitation of the real world, based on pre-developed models, can open an entirely new methodology in art and science. Thus, understanding the differences between representation and simulation among students and researchers who use drawings in their work should be a first step in improving the overall quality of the results. Questioning about the relations between accuracy-validity and objectivity-subjectivity, while using drawings in research, is also a result of the digital simulations age. Downes \& Lange (2015) have considered the factors that influence our sensory perception of the environment and the variations occurring while experiencing an environment on site, compared to viewing a visualization. In this case, drawings with high level of personalization remain subjective. 
Although they are the only visual legacies we have from the landscapes of the past, old drawings or historical illustrations are rarely used in urban research, planning and design, because of their reduced credibility or relevance. The most dynamic interactions between natural and anthropological factors which create cultural landscapes can be found in the urban area, where often the landscapes accumulate features from several distinct periods of time, similar to a palimpsest. Antrop (2005) considers that is important for the legibility of the landscape to tell the history of a place, which strongly enhances the identity and the overall value, explaining further how the past is relevant for the sustainable planning of future landscapes. In this case, historical illustrations may be considered as an important source of information, now more accessible using dedicated technologies.

Historical illustrations may refer to a drawing, photograph or to any kind of picture designed to complement a text in a publication from the past, especially from the $18^{\text {th }}$ and $19^{\text {th }}$ century or before, but not necessarily. A lithograph from the $16^{\text {th }}$ century is certainly historical, but also a photograph from the $21^{\text {st }}$ century capturing something that has been changed or does not exist anymore; in this case, a chronological delimitation is not always enough. For instance, in cultural studies, text and illustrations are cultural artefacts. According to Hall et al. (2009), culture is about "shared meanings" and "language is the privileged medium in which we make sense of things, in which meaning is produced and exchanged" (p. 1). This way, language as sounds, written words, images and all kinds of objects represent concepts, ideas and feelings; in this case, a chronological delimitation is no longer highly relevant. Returning to the relationship between representation and simulation is now appropriate, since now it becomes clear that in social sciences and art, representation remains an ethical concern of construction, while, in more formal sciences, simulation is more adequate. Yet, representation and simulation are part of a whole in which one dominates the other, depending on the context and on the research objectives.

\section{METHODOLOGY}

Using illustrations can improve the overall quality of a publication, good pictures or drawings can be considered a universal language which completes the text, improving the transmission of information from authors to readers. Reading and interpreting illustrations will always reveal new information. Rose (2002) draws attention to the fact that "visual imagery is never innocent; it is always constructed through various practices, technologies and knowledges" (p. 32) Regarding the results that may be obtained by interpreting visual images, it should be mentioned that the only limits are imposed by the interpreter, by his critical and scientific ways of thinking, by attention to detail and knowledge about the subject (Maroși, 2015).

Interpretation of visual images cannot be associated with a clear method of work which ensures the interpreter to achieve the desired results. Every interpretation is based on a personalised methodology, known as visual methodology, which outlines the most common and most applicable practices in the field. For example, in cultural studies, interpretation of images regarded as cultural artefacts - should begin by following the five aspects of the "circuit of culture": representation, identity, production, consumption and regulation (Hall et al., 2009, p. 1). In art and design, the interpretation of visual images most often begins with a structural and compositional analysis continued with detailed evaluations of the aesthetic sensation, originality and representation (Barber, 2004). In architecture and urban design, technical drawing and descriptive geometry can be seen as a language used to express proportions, shapes, volumes and surfaces in space, and more importantly, to make a scale drawing of a proposed structure as it will actually appear to the observer when it is built. Yet, among the most illustrated books 
are certainly those with geographical topics, making Geography a highly "visual science", not because of the descriptive character, wrongly associated with this science, but for its global approaches and vision of the world. For geographers, illustrations and maps are the only way to study the whole and its characteristics through indirect observation. However, geographical observation is more than just "to see". In addition, to reflect about the surrounding reality, observation continues with the processing and interpretation of images that we perceive directly from nature or indirectly, by using substitutes such as maps, photographs, drawings, videos, holograms or other interactive 3D models which simulate nature (Maroși, 2015).

Although there is a multitude of different approaches regarding the use of visual images in research, there are also concerns to emphasize the common aspects of visual methodologies and therefore reducing the subjectivity of image interpretation. A methodological framework for interpreting visual images in social sciences was developed by Rose $(2002$, p. 17) and it consists of "the three sites at which the meanings of an image are made: the site(s) of the production of an image, the site of the image itself, and the site(s) where it is seen by various audiences." In this case, each site can be detailed in different modalities, and the importance of each site can be adjusted to the research goals, in a personalised and flexible manner.

\section{Choosing and referencing illustrations}

Sources of appropriate illustrations can be found in the most unexpected places, the great variety of publications covers many scientific fields from different periods, different places, and cultures. Narrowing the options by creating a list of interests and goals should be a first step, followed by finding an image which arouse curiosity. Afterwards, a full citation which legitimates a reliable source is required. Commonly, the audience is satisfied with a quick view of the pictures, unintentionally avoiding the background information and details.

For instance, our purpose is to achieve a survey of urban history which means that historical illustrations, lithographs, engravings, drawings, and photographs should be sought. In this specific case, we are focusing on the medieval defensive walls constructed around the city of Cluj-Napoca, walls that were largely demolished in the $19^{\text {th }}$ century. Early on, we have decided to visit three of the major museums in Cluj-Napoca: The National Museum of Transylvanian History, The Transylvanian Museum of Ethnography, and The Art Museum. Unfortunately, The Museum of Transylvanian History was partially closed to the public in July 2016, the only open section was The Roman Times of Dacia where an interactive simulation allowed visitors to explore the ruins of the ancient city Ulpia Traiana Sarmizegetusa. Before we left, we have been assured by the guide that the museum does not have historical illustrations, but they store a few fragments of carved stone from the original towers and gates. Checking the souvenir shop was followed by the identification among the displayed postcards of one illustration of an engraving, without any reference, showing the city of Cluj in the $18^{\text {th }}$ century (Figure 6). The Museum of Ethnography had a beautiful thematic collection of historical photographs, but, to our disappointment, not about this city's history.

Considering the fact that before the $20^{\text {th }}$ century, in the time of the Austro-Hungarian Empire, Cluj-Napoca was known under the names Klausenburg (in German) and Kolozsvár (in Hungarian), using the old names in the search engines has increased the number of the results. Some of the relevant documents were available in digital form, other titles had to be searched in libraries. Further on (at point 3 below: Interpretation of historical illustrations), each illustration will be described separately, in chronological order. 


\section{Redrawing illustrations using the atmospheric perspective}

For historical illustrations, time is corrosive in terms of preserving information, but it is also contributing by constantly enriching the cultural significance and value of any kind of artefact. Therefore, the first purpose of a redraw should be to fill the gaps caused by aging and also to keep the historical information in circulation, by interpreting them using the present context. This is a reliable way to strengthen the identity and the overall value of a specific place, enhancing the feeling of belonging and attachment to a place and to a social group, things that are desired for a rooted sustainable development.

Atmospheric perspective is a drawing technique which emphasizes the illusion of depth based on the tendency of objects to grow paler and less detailed as they recede into the distance, observable while looking at the horizon (Figure 1). The most important reason for using this perspective in redrawing historical illustrations is to set one's sights on the relevant elements and improving the interpretation, giving new life to old drawings, engravings, and photographs.
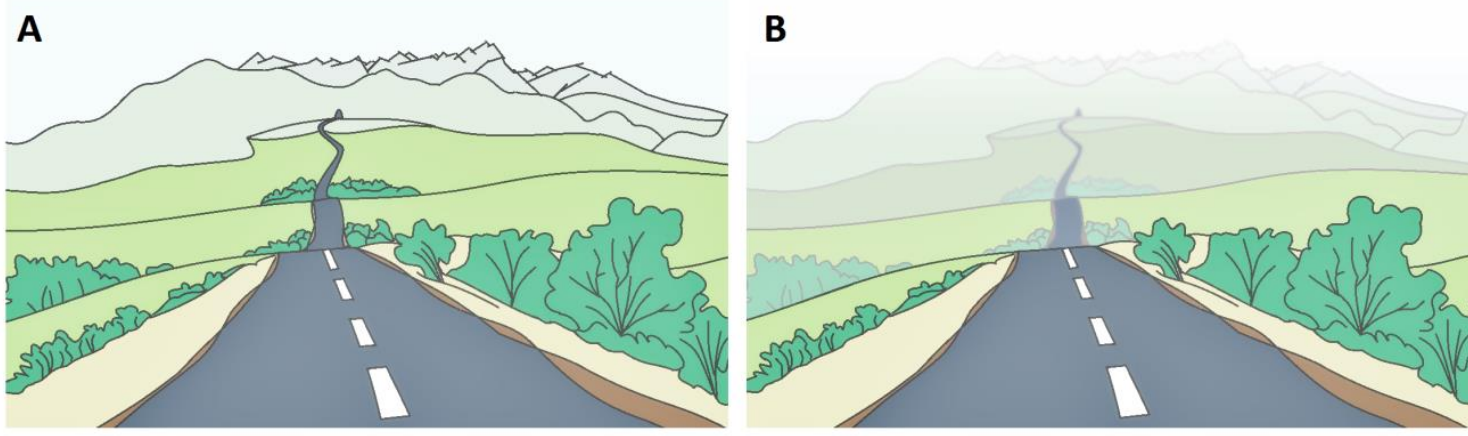

Figure 1: Creating the illusion of depth using the atmospheric perspective, $A$ - without the atmospheric perspective, $\mathrm{B}$ - with the atmospheric perspective

Drawing by Maroși Zoltan, 2016 (using PhotoScape)

Digital redrawing of illustrations, besides the personal computer, requires a graphics tablet which allows a user to hand-draw images directly in digital form, replacing the mouse. Considering that the majority of libraries have very good scanners available to the subscribers, a personal scanner with high optical density and resolution (with 300-360 dpi/ppi recommended) is no longer needed. Depending on the type of drawing, there are recommended different graphics software, distinct categories of graphics (raster or vector) require matching programmes that allow efficient image editing. Buying the licenses for professional software can be expensive, but it is recommended for the best results in extensive projects. Open source alternatives to expensive software can be found, but with editing restrictions and fewer editing tools. Still, they are enough for learning and for a wide range of smaller projects. For instance, technical drawings are mostly based on vector graphics for which AutoCAD (Computer-Aided Design), developed by Autodesk, is preferred by many architects, designers, and engineers. For the more common raster graphics, there is plenty of specialised software, mostly used for editing photographs, but also useful for digital drawing (Paricio, 2015, pp. 159-212). Among the most popular photo editing software packages are those from "The Adobe Photoshop Family", but, unfortunately, they are limited only to editing raster graphics and are not for efficient drawing. Overall, the most recommended software designed both for drawing and editing are: CorelDraw, Inkscape, Macromedia Freehand, GIMB (GNU Image Manipulation Program) and the reliable Microsoft Paint known for its simplicity, introducing many to painting on a computer for the first time, still widely used for very simple image manipulation tasks. However, the best way to achieve the desired results is to use the most familiar software available, therefore a general approach is more appropriate. 


\section{Interpretation of historical illustrations}

Finding Conrad von Weiss's drawing Prospect der Ungarischen Stadt Clausenburg (Borbély, 1943 , p. 20) joined by the explicit footnotes and a very detailed map for those times, raised questions about the author and his reasons. Kaiserlicher Offizier-Ingenieur Conrad von Weiss, was, as indicated by his titles, an imperial officer and a military engineer delegated to assess the state of the defensive infrastructure of Transylvania. His collection of maps and drawings illustrating the cities of Transylvania was the first complete military survey of this territory, making the preparations for the Josephinian Land Survey conducted from 1763 to 1787.

The illustration locates the following buildings, as indicated by footnotes (Figure 2): i. Das Schloss (The Castle), 2. Der Dom (St. Michael's Church), 3. Jesuitenkirche (The Jesuits' Church), 4. Die Franziskanische Kirche (The Franciscans' Church), 5. Die Schulen (The Schools), 6. Das Evangelische Bethaus (The Evangelical House of Prayer), 7. Die Calvinistische Kirche (The Calvinist Church), 8. Das Calvinistisches Kollegium (The Calvinist College), 9. Das Mitteltor (The Middle Gate), 10. Das Mühl Tor (The Mill Gate), ii. Das Münstertor (The Monostor Gate or the Monastery Gate), 12. Graben / Begräbnisse (Graves) 13. Die Arianischen Bethäuser (Arians' Houses of Prayer).

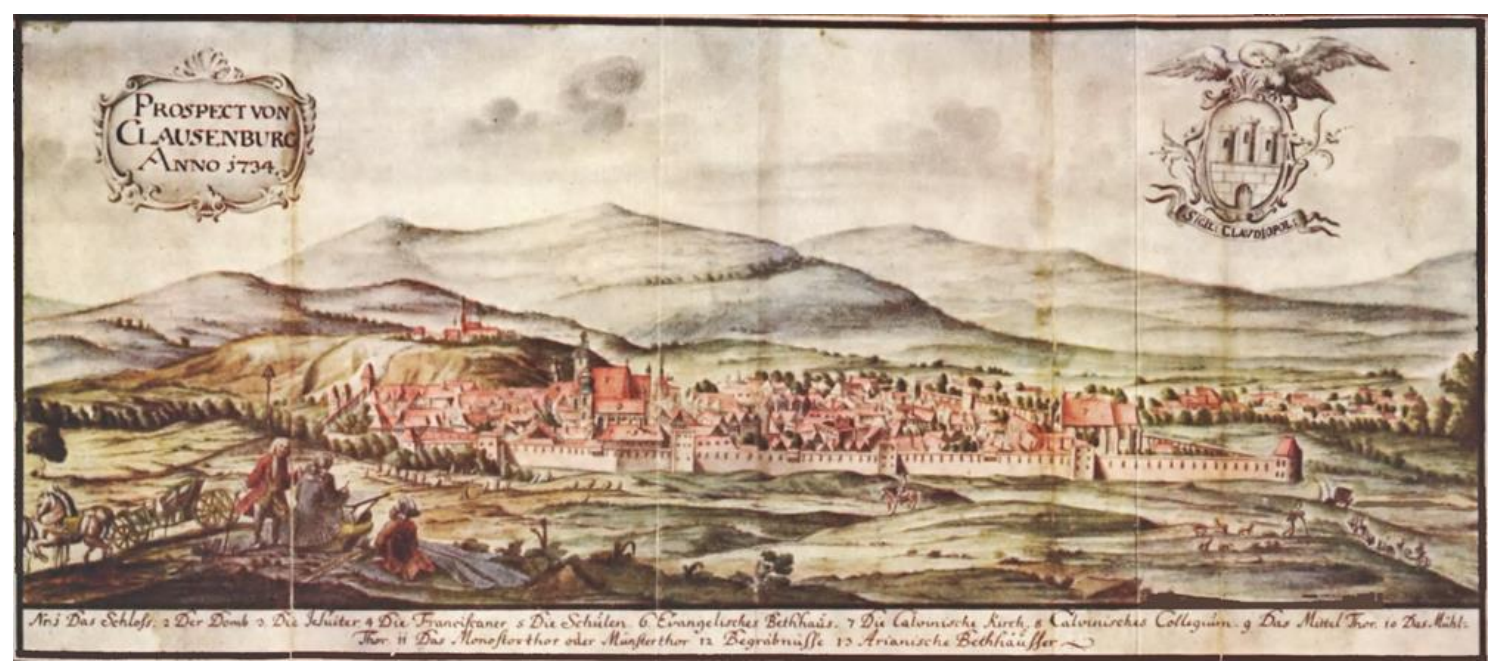

Figure 2: Conrad von Weiss, 1734, Prospect von Clausenburg - drawing illustrating the southern side of the medieval fortifications of Cluj-Napoca

Source: Borbély Andor, 1943, p. 20

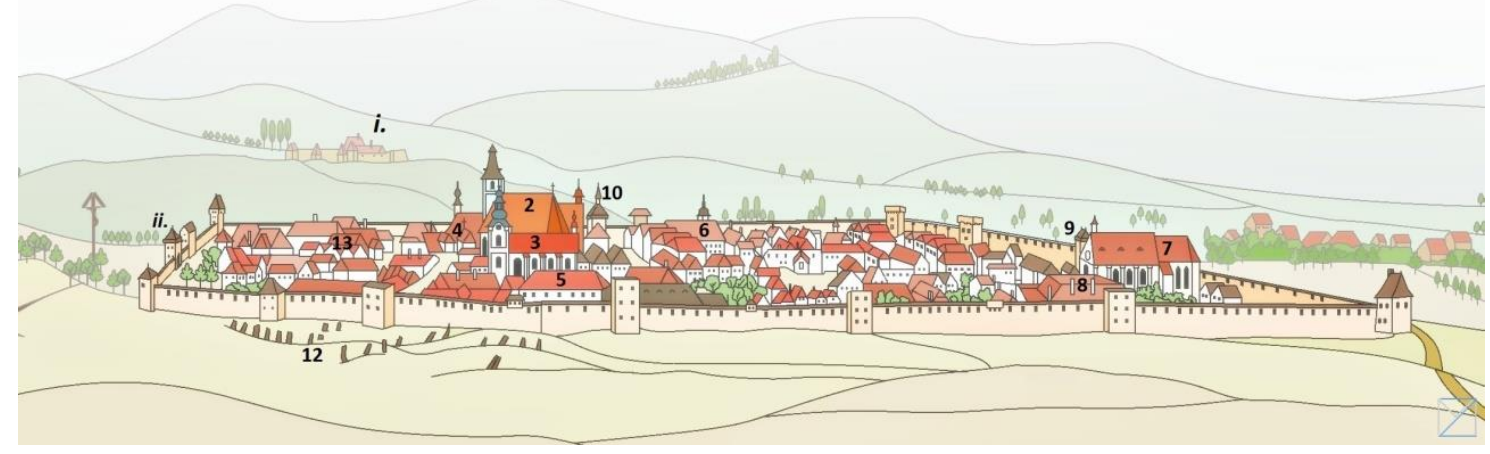

Figure 3: Digital Redrawing of Conrad von Weiss's 1734 Drawing of Cluj-Napoca 
The less realistic drawing made by János Szakáll, a former goldsmith from Cluj, is significant for the Catholic Counter-Reformation period, when the Baroque style was used to impress the population of Cluj. During this Catholic Reformation, St. Michael's Church Baroque tower (2) was built, finished in 1744, and demolished in 1763, because of the damages caused by an earthquake. The Franciscans' Church Baroqe tower (4) and the new Jesuits' Baroque Church (3) were built between 1724 and 1728. Representing this short period of time, the drawing is very valuable. The copperplate engraving was signed by someone named Clowi, but an examination carried out by Jakab (1870, p. 536) concluded that the signature is not clear enough to reveal the full name. The provided annotations for Figures 3, 5 and 7 are corresponding to each other, making the comparison between drawings easier.

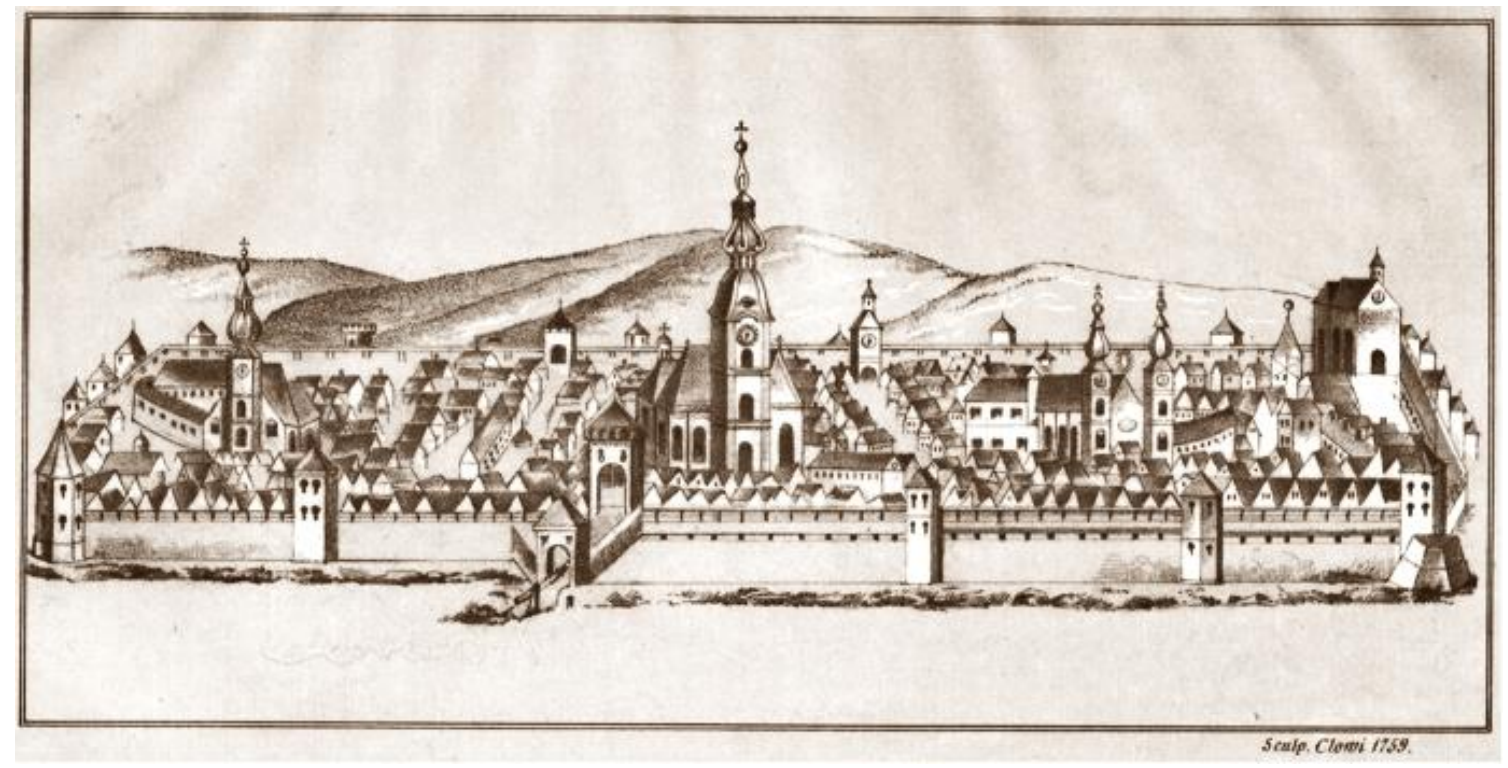

Figure 4: János Szakáll, 1759, View over the West Side of the Medieval Fortifications of ClujNapoca, drawing and copperplate engraving

Source: Jakab Elek, 1870, p. 536

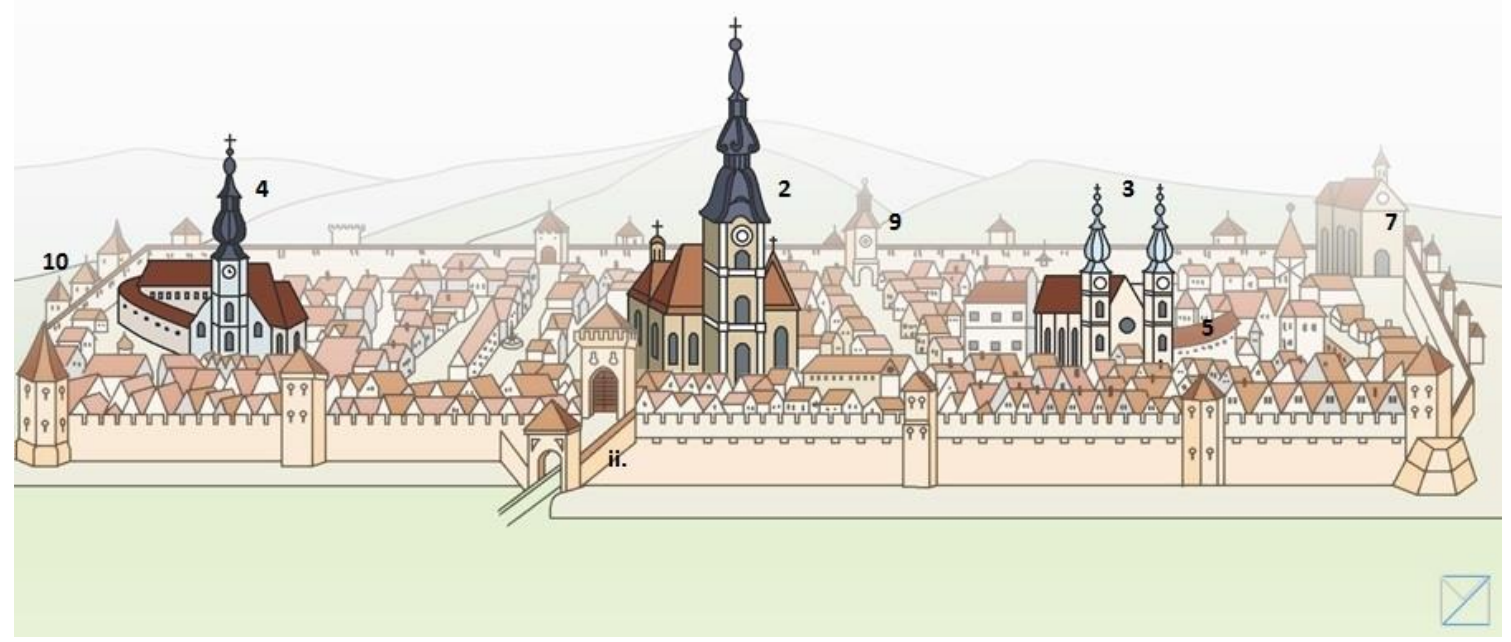

Figure 5: Digital Redrawing of János Szakáll's 1759 Drawing of Cluj-Napoca 
The following engraving (Figure 6) was used in the latest publications without references to the original sources or other descriptions. Postcards depicting this engraving can be purchased from The History Museum of Transylvania from Cluj-Napoca, with the following title written on the back: The City of Cluj in $18^{\text {th }}$ century, engraving. Pascu (1974, p. 256) used the image in Istoria Clujului (History of Cluj), mentioning only the year of the engraving. Further details about this image can be found in Jakab's Kolozsvár története (History of Cluj), where it is mentioned that the surname of the author is Simon, but the given name was unreadable because of deterioration (Jakab, 1870, p. 536). It is mentioned that the Baroque framed engraving was made for the Locksmiths Guild of Cluj-Napoca (ornamental keys can be seen on the left side of the city emblem). Multiple replicates were made over the years.

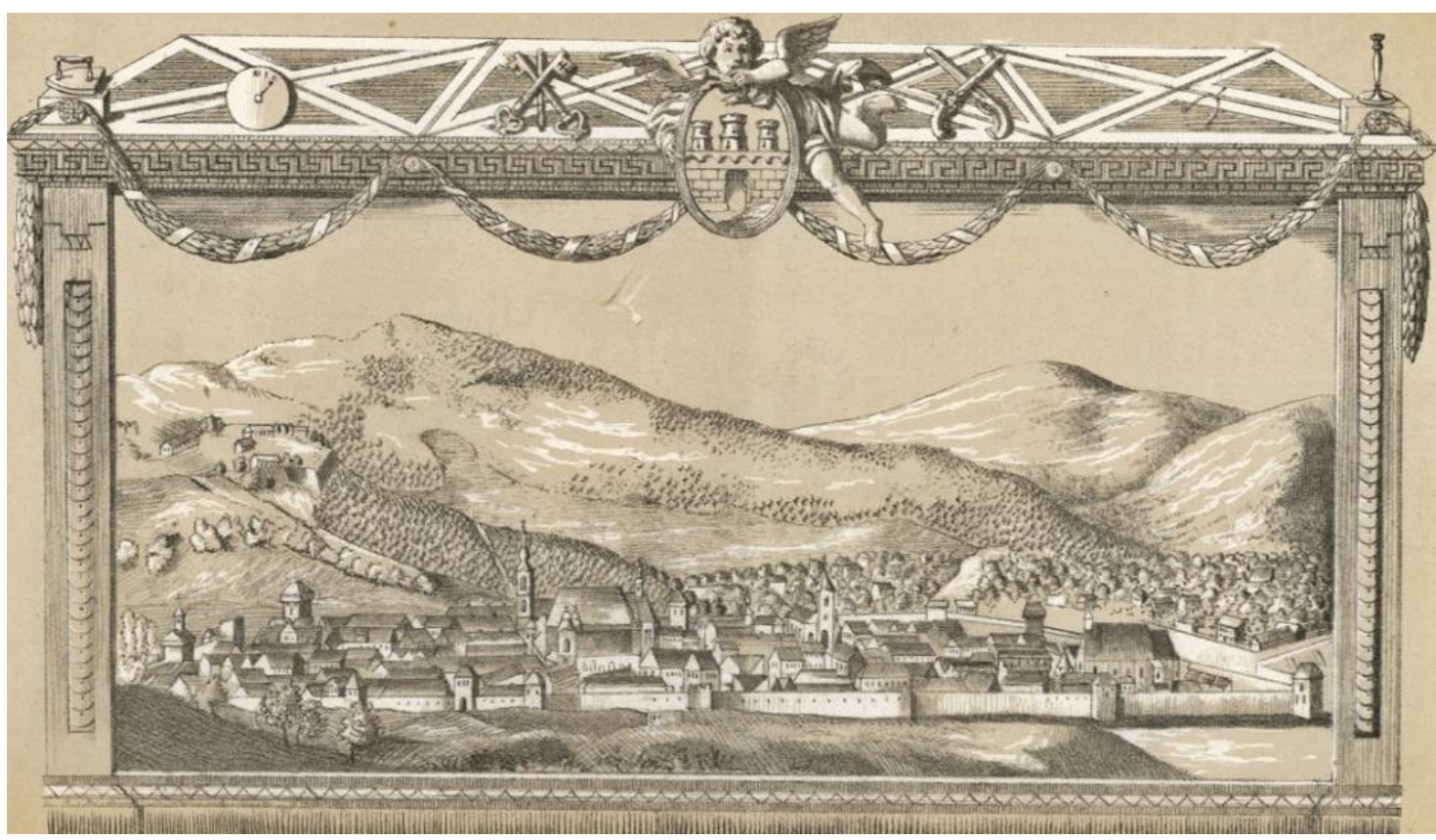

Figure 6: Simon, 1798, View over the South Side of the Medieval Fortifications of Cluj-Napoca, Baroque framed engraving made for the Locksmiths Guild of Cluj-Napoca

Source: Jakab Elek, 1870, p. 536

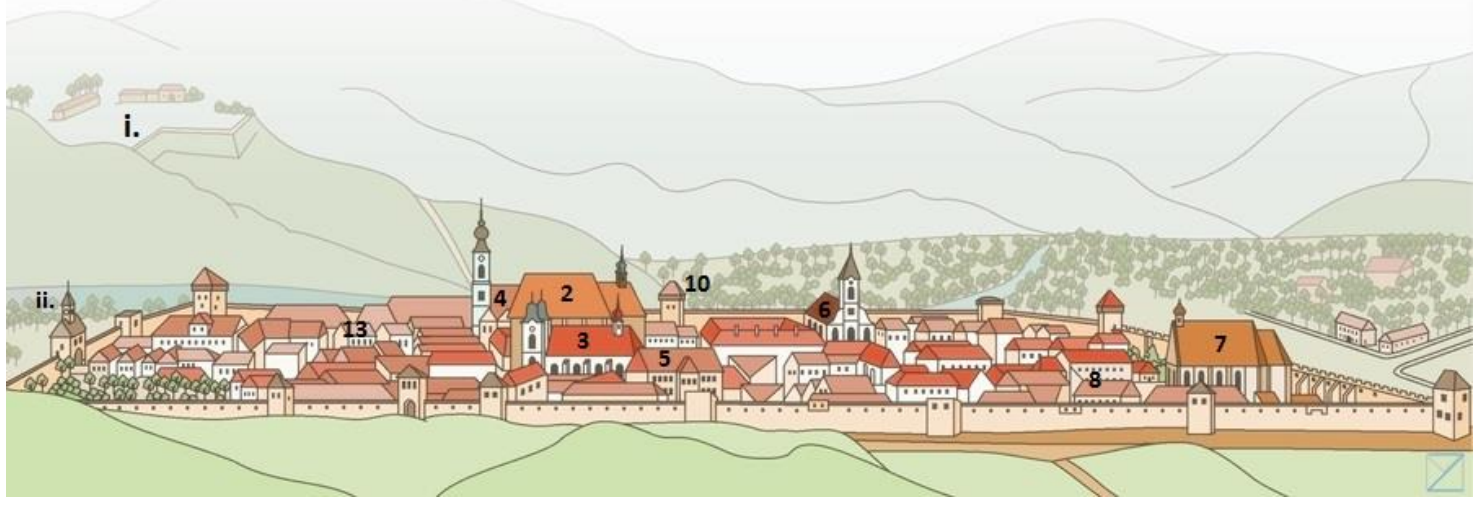

Figure 7: Digital Redrawing of Simon's 1798 engraving of Cluj-Napoca 
One of the first chief architects of Cluj-Napoca was Lajos Pákey (1853-1921), whose drawings were the last accurate representations of the original towers and bastions of Cluj-Napoca before the demolition from the beginning of the $19^{\text {th }}$ century (Figure 8 ). Pákey was against the demolition of the old fortifications, but the lack of funds and space led to the sale of the walls, and the building materials resulted from the demolition were used in the new constructions. The following towers were sketched (Figure 9): I. The Locksmiths' Tower or The Gate of the Bridge, II. The Goldsmiths' Tower, III. The Tailors' Bastion (still exists), IV. The Hungarians' Gate, V. The Firefighters' Tower (still exists), and. VI. The Middle Gate.

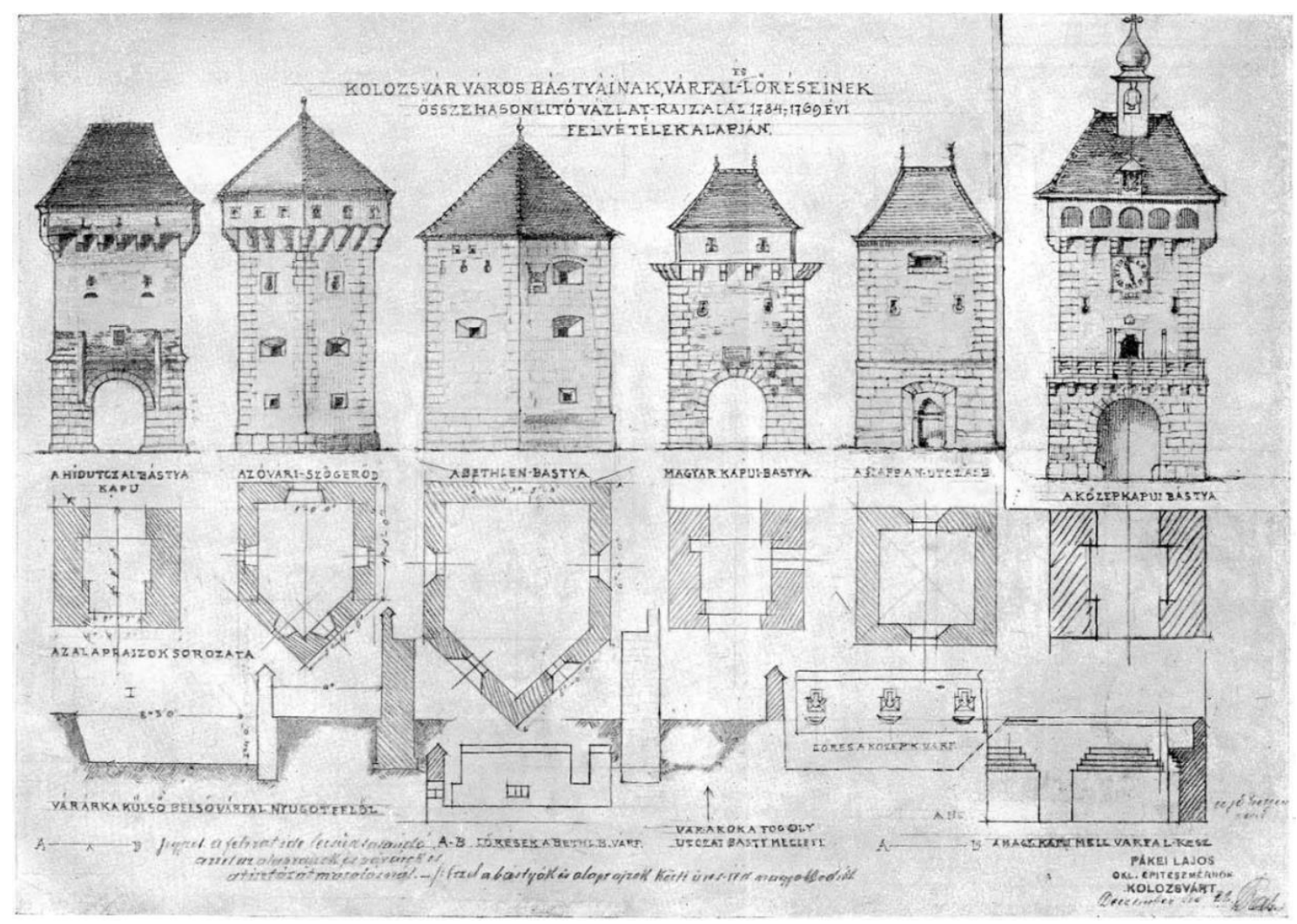

Figure 8: Lajos Pákey, Bastions and Towers of Cluj-Napoca, architectural sketches

Source: Balogh Jolán, 1944, p. 14

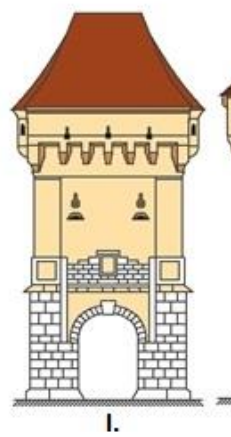

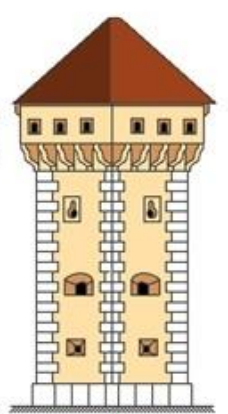

II.

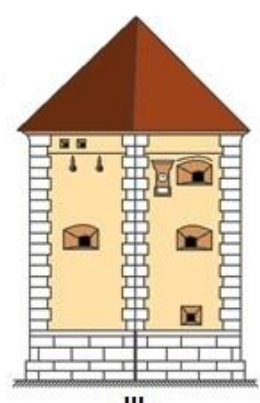

III.

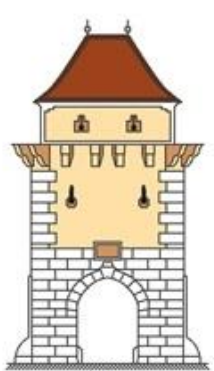

IV.

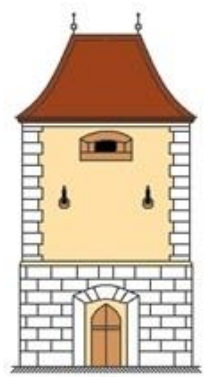

v.

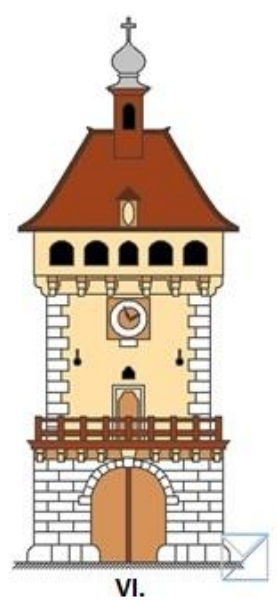

VI.

Figure 9: Digital Redrawing of Lajos Pákey's sketches of the Bastions and Towers in Cluj-Napoca 


\section{The subjectivity of historical illustrations}

Visual representations of the complex reality, even using the most advanced techniques, are subjective to a certain degree. The thin line between subjective and objective is drawn by the people's perception of the reality through visual representations, in which accuracy is decisive. The level of accuracy for a visual representation is determined by the number of details recognised by the audience, yet Downes \& Lange (2015) point out that through representations the level of accuracy is not clear and "for many situations exact accuracy may not be required". (p. 137). This selective way of choosing the most relevant details in visual representations is one of the most important advantages of drawings against photographs, while fading the less important details that can obstruct attention should not be considered as a reduction in accuracy. Drawings with specific purposes, made with a lower degree of accuracy and therefore a lower degree of realism can still contain the most relevant information for specific cases. The planning disciplines rely on such drawings and other abstracted representations of reality and Lange $(2001$, p. 167) compares the photographic reality with the virtual created landscapes, presenting an empirical study about the required level of realism ( $R^{\prime}$ Degree) in simulations to be validated as accurate and reliable. Surprisingly, the results confirm that virtual created landscapes can be perceived as equal as or better than photographic reality in specific cases. However, this results are related only to the digital created landscapes using advanced technologies, with a large opening towards the future.

Historical illustrations can be regarded as a representation of the past constructed on a set of details selected by the author. Often, the most important details for the author's purposes are emphasized by reducing the proportionality of the drawing (in our case the churches and the fortifications are the most important, therefore they appear larger). On the other hand, the more irrelevant details are represented through repetitive elements (in our case the houses are represented almost identically, effect caused by the distance). Although these deviations from the expected details increase the subjectivity of the illustrations, their descriptive quality remains unaffected (Figure 10):

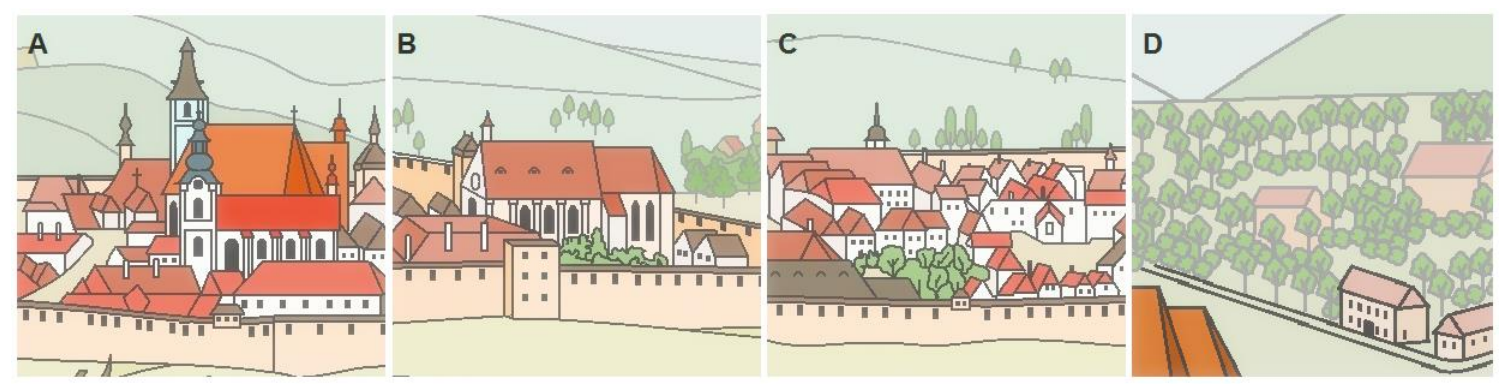

Figure 10: Emphasized details - A, B and repetitive elements (buildings and vegetation) - C, D Drawing by Maroși Zoltan, 2016

Redrawing historical illustrations involves tracking the same steps taken by the authors long time ago, making the interpretation more personal and therefore more efficient. A redrawn illustration will enable the following possibilities: (1) changing the zoom without losing the image quality, (2) editing the properties of the digital drawn lines, (3) editing colours for a better effect of space, (4) overlapping and comparison of several redrawn illustrations, (5) completing the drawing with more details from other relevant sources of information, and (6) combining different drawings and maps for a highly descriptive collage or an investigation board. In our case, a virtual reconstruction of the fortifications of Cluj-Napoca can be achieved (Figure 11). 

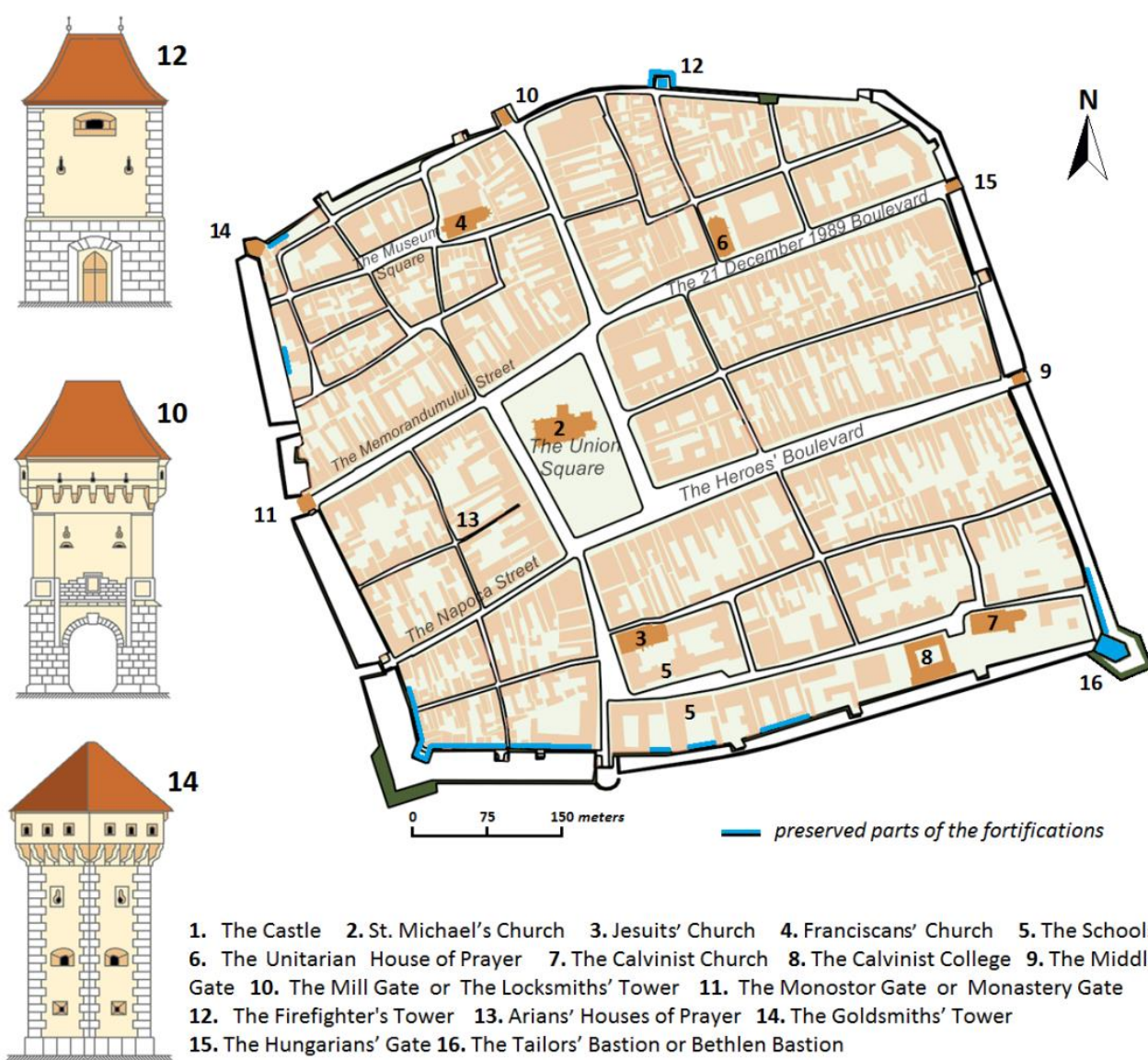

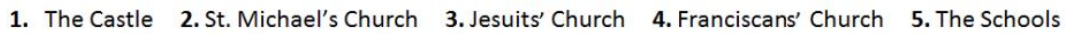
6. The Unitarian House of Prayer 7. The Calvinist Church 8. The Calvinist College 9. The Middle Gate 10. The Mill Gate or The Locksmiths' Tower 11. The Monostor Gate or Monastery Gate 12. The Firefighter's Tower 13. Arians' Houses of Prayer 14. The Goldsmiths' Tower 15. The Hungarians' Gate 16. The Tailors' Bastion or Bethlen Bastion
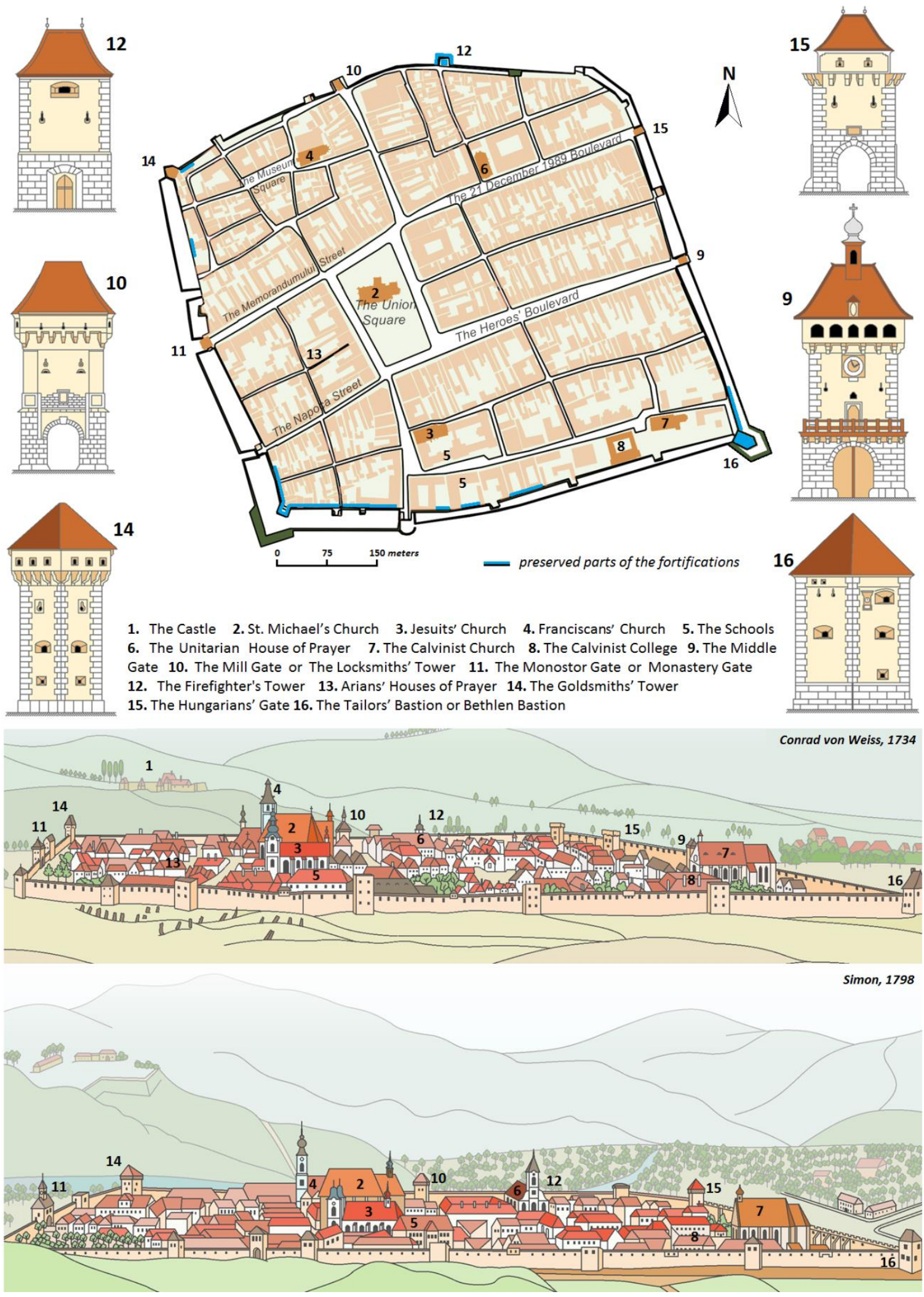

Figure 11: The Fortification of Cluj-Napoca, as shown in the historical illustrations

Drawings and map by Maroși Zoltan, 2016 


\section{The popularity and veracity of historical illustrations}

The veracity as a scientific instrument for measuring accuracy should not be blended with the level of popularity, considering that the most realistic historical illustrations are not always the most popular. This means that the validation of the accuracy based on the public perception will not provide reliable results, therefore a selection of several groups of local-experts could be a solution. Eventually, the most important aspect in using images for research relies on the identification of sources and the detailed descriptions of the content, things that are usually lost by repeated copying and data transmission on the internet. For historical illustrations, the local archives and old publications continue to be the best sources.

In certain circumstances, on websites and web forums with specific topics, urban myths are born due to misunderstanding and misinformation, and sometimes they become more popular than the reality. For example, one of the most popular and well known historical illustration of ClujNapoca, illustrated on telephone cards, bank cards, postcards and other publications, is Egidius van der Rye's Claudiopolis Coloswar vulgo Clausenburg Transilvaniae civitas primaria (Figure 12), which is distinguished more by the artistic representation of an imagined Claudiopolis, based more on written descriptions than on direct observations.

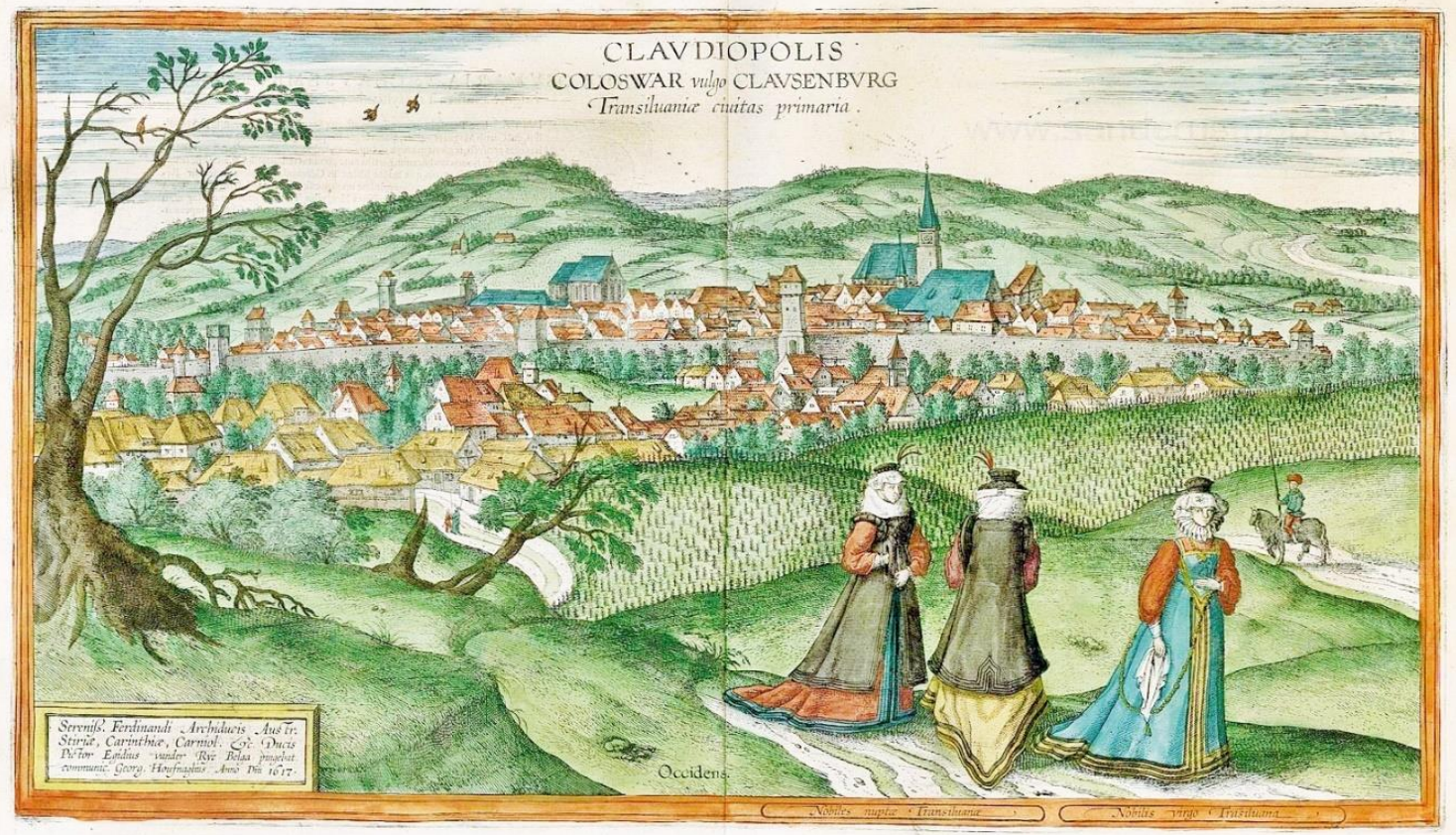

Figure 12: Egidius van der Rye, 1617, Claudiopolis Coloswar vulgo Clausenburg Transilvaniae civitas primaria, produced by Georg Hoefnagel, copper engraving, 30.5 x $52.5 \mathrm{~cm}$

Source: Sanderus Catalogue, 2016

According to Sanderus Catalogue (2016), the attached cartouche contains the following translated text: "For Ferdinand, Archduke of Austria, Duke of Styria, Carinthia, etc., painted by the Belgian artist Egidius van der Rye and produced by Georg Hoefnagel in the year 1617." The illustration is part of a large collection of maps and engravings, which put together form the monumental Civitates orbis terrarum, edited in six volumes by Georg Braun and largely engraved by Franz Hogenberg between 1572 and 1617. It is clear that the illustrations were made in uniform style, ornaments being added to decrease the strategic character and to increase the popularity of the atlas through an artistic approach. 


\section{The relevance of digital redrawings}

The exact selection of illustrations based on the research purposes and in accordance with the specialisation and preferences of the interpreter should lead the research to a higher level. It is recommended that the same images or illustrations to be interpreted by more than one person and their results to be compared (Bohnsack, 2010, p. 274). Overlaying more results and reviews should increase the credibility of the research; the limits are given only by the critical sense, attention to details, scientific preparation, and creativity of the interpreter.

Lately, the medieval fortifications and city walls from Transylvania have aroused urbanists' interest and, after several questionable restorations, the public opinion is paying more attention to these. Major fortresses have been restored without taking into account historical illustrations and written descriptions about the original structures. Major deviations from the original appearance of some towers and bastions have been made through rehabilitations (The Fortress of Deva, Mălăiești Castle, The Urban Fortifications of Mediaș, and hundreds of other historical buildings in Transylvania). These events encourage the usage of historical illustrations and demonstrate the need for interdisciplinary studies in the area of architecture and urbanism. Besides the mentioned aspect, redrawing historical illustrations is relevant for (1) refreshing the urban memory and identity of historical cities, (2) the delimitation historical buildings and their related protection zones with specific regulations, (3) the delimitation of central zones and other functional areas, as an important process of urban planning, (4) researching the origins of urban morphology, influenced by the fortification systems and by other parts of historical infrastructure, and for (5) the urban evolution and for many other small-scale restorations.

Popularisation of the defensive architecture in Transylvania, through drawings and other graphical reconstructions, can be found in Cetăți, castele și alte fortificații din România [Fortresses, Castles and Other Fortifications from Romania. From the Beginnings until 1540] (Oltean, 2016, pp. 1-103), a publication which explains not only through words, but above all, through images. The same author has published several posters with medieval fortified cities of Transylvania, contributing greatly to the revitalisation of the urban memory and to local tourism.

Starting with the $19^{\text {th }}$ century, photographs have become very popular, replacing the subjective drawings and engravings. There are several photographs which capture the last years of the fortifications of Cluj-Napoca, providing valuable details about the exact position of certain parts of the fortifications and also about the technical information for the structures. Interpretation of photographs allows measuring techniques and planimetry to be applied; in other words, more detailed and more credible results can be achieved (Maroși, 2015, pp. 117-118). In this case, we consider the present approach to be only an introductory research about the potential and applicability of historical illustrations in urban research, design, and planning.

\section{CONCLUSIONS}

In this research, the following results have been achieved: (1) encouraging the usage of illustrations as a reliable source of information during research, (2) identifying the sources of historical illustrations, (3) redrawing of historical illustrations using digital drawings for more efficient interpretation, (4) the interpretation and comparison of different sources of illustrations, (5) the virtual reconstruction of the fortifications of Cluj-Napoca using historical illustrations, and (6) rediscovering genuine urban features, looking back into the past in order to "rediscover the rationale for decoration. Without such a rationale, decoration and ornament in 
the city may be seen as fussy, precious and florid, a veneer to cover cheap and shoddy development" (Moughtin et al., 1999, p. 16).

\section{On using the historical illustrations included in this paper}

In Romania, according to Law no. 8 from the $14^{\text {th }}$ of March 1996, concerning the copyright and the related rights, Chapter 10, Article 85, Paragraph 2, photographs of letters, deeds, and documents of any kind, technical drawings and other such documents cannot benefit from the legal protection of copyright. http://www.cdep.ro/pls/legis/legis_pck.htp_act_text?idt=10396 Moreover, the author of this paper (Maroşi Zoltan) worked with copied copies of the original illustrations, even if he mentioned the authors of those original illustrations.

\section{REFERENCES}

ANTROP, M. (2005). Why Landscapes of the Past are Important for the Future. Landscape and Urban Planning. Rural Landscapes: Past Processes and Future Strategies, 70(1), 21-34.

BALOGH, J. (1944). Pákei Lajos rajzai Kolozsvár építészeti emlékeiröl [Pákei Lajos's Drawings of the Architectural Monuments in Kolozsvár]. Kolozsvár: Az Erdélyi Múzeum-Egyesület kiadasa. Retrieved July 20 2016, from http://mek.oszk.hu/08400/08496/08496.pdf

BARBER, B. (2004). Structure and Anatomy of Landscape. In: BARBER, B. (ed.), The Fundamentals of Drawing Landscapes. A Practical and Inspirational Course (pp. 32-64). Leicester: Arcturus Publishing Limited.

BOHNSACK, R. (2010). The Interpretation of Pictures and the Documentary Method. In: BOHNSACK, R., PFAFF, N., \& WELLER, W. (eds.), Qualitative Analysis and Documentary Methods in International Educational Research (pp. 267-343). Opladen \& Farmington Hills: Barbara Budrich Publishers.

BORBÉLY, A. (1943). Erdélyi városok képeskönyve 1736-ból [Picture Book from 1736 of Transylvanian Towns]. Kolozsvár: Az Erdélyi Múzeum-Egyesület kiadasa.

DOWNES, M., \& LANGE, E. (2015). What You See Is Not Always What You Get: A Qualitative, Comparative Analysis of Ex Ante Visualizations with Ex Post Photography of Landscape and Architectural Projects. Landscape and Urban Planning, 142(1), 136-146.

HALL, S. (2009). The Work of Representation. In: HALL, S. (ed.), Representation: Cultural Representations and Signifying Practices (pp. 13-75). London: Sage.

JAKAB, E. (1870). Kolozsvár története. Első kötet [History of Kolozsvár. Volum I]. Budapest: Magyar Királyi Egyetemi Nyomda.

LANGE, E. (2001). The Limits of Realism: Perception of Virtual Landscapes. Landscape and Urban Planning, 54(1), 163-182.

MAROȘI, Z. (2015). The Relevance of Using Photographs in Geographical Research. Geographia Napocensis, 9(1), 109-119.

MOUGHTIN, C., OC, T., \& TIESDELL, S. (1999). Theory and Philosophy of Ornament and Decoration. In: MOUGHTIN, C., OC, T., \& TIESDELL, S. (eds.), Urban Design: Ornament and Decoration, 2nd edition (pp. 1-25). Oxford, Great Britain: Architectural Press. 
OLTEAN, R. (2016). Cetăți, castele și alte fortificații din România. De la începuturi până spre anul 1540 [Fortresses, Castles and Other Fortifications from Romania. From the Beginnings until 1540]. Bucharest: Art Historia.

PARICIO, J. (2015). Photoshop Painting. In: PARICIO, J. (ed.), Perspective Sketching. Freehand and Digital Drawing Techniques for Artists \& Designers (pp. 159-212). Beverly, Massachusetts, USA: Rockport Publishers.

PASCU, S. (1974). Istoria Clujului [History of Cluj]. Cluj-Napoca: Consiliul Popular al Municipiului ClujNapoca.

ROSE, G. (2001). Researching visual materials: towards a critical visual methodology. In: ROSE, G. (ed.), Visual Methodologies. An Introduction to the Interpretation of Visual Materials (pp. 5-33). London: Sage.

SANDERUS CATALOGUE (2016). Antique map of Romania - Cluj-Napoca by Braun \& Hogenberg. Retrieved July 29 2016, from https://www.sanderusmaps.com/detail.cfm?c=5631

SCHEER, D.R. (2014). The Death of Drawing: Architecture in the Age of Simulation. London and New York: Routledge. 